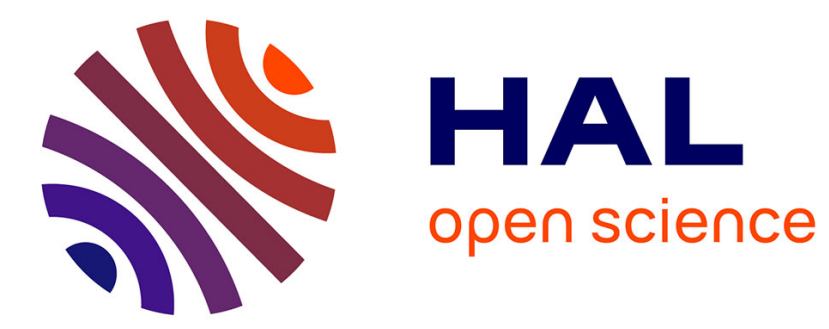

\title{
At the Limits: What Drives Experiences of the Sublime
} Margherita Arcangeli, Jérôme Dokic

\section{To cite this version:}

Margherita Arcangeli, Jérôme Dokic. At the Limits: What Drives Experiences of the Sublime. British Journal of Aesthetics, 2021, 61 (2), pp.145-161. 10.1093/aesthj/ayaa030 . ijn_03498627

\section{HAL Id: ijn_03498627 \\ https://hal.science/ijn_03498627}

Submitted on 21 Dec 2021

HAL is a multi-disciplinary open access archive for the deposit and dissemination of scientific research documents, whether they are published or not. The documents may come from teaching and research institutions in France or abroad, or from public or private research centers.
L'archive ouverte pluridisciplinaire HAL, est destinée au dépôt et à la diffusion de documents scientifiques de niveau recherche, publiés ou non, émanant des établissements d'enseignement et de recherche français ou étrangers, des laboratoires publics ou privés. 


\title{
AT THE LIMITS: WHAT DRIVES EXPERIENCES OF THE SUBLIME
}

\author{
Margherita Arcangeli and Jérôme Dokic \\ Institut Jean Nicod (CNRS-EHESS-ENS), PSL University
}

\begin{abstract}
Aesthetics, both in its theoretical and empirical forms, has seen a renewed interest in the sublime, an aesthetic category dear to traditional philosophers, but quite neglected by contemporary philosophy. Our aim is to offer a novel perspective on the experience of the sublime. More precisely, our hypothesis is that the latter arises from 'a radical limit-experience', which is a metacognitve awareness of the limits of our cognitive capacities as we are confronted with something indefinitely greater or more powerful than us. This hypothesis better explains the negative feelings involved in the experience of the sublime and accounts for its demarcation from other experiences (for example, terrible beauty). Experiences of the sublime have an overall positive valence, though. We will explore different ways in which a subject can try to overcome the negative evaluation involved in radical limit-experiences, and suggest that only one of them is appropriate to experiences of the sublime.
\end{abstract}

\section{INTRODUCTION}

The sublime as an aesthetic category has been historically dear to philosophers, but it has been rather neglected in contemporary philosophy. Currently, however, there is a revival of interest (see, e.g., Cochrane, 2012; Brady, 2013; Shapsay, 2013) and even experimental psychology got a hold of it (see, e.g., Ishizu \& Zeki, 2014; Pelowski 2019). Literary fiction offers powerful descriptions of the sublime. Here are a couple of examples. While the first, from Thomas Mann's The Magic Mountain, deals with the natural sublime, the second, from Philip Roth's American Pastoral, illustrates a more artificial sublime.

But if there was something roguish and fantastic about the immediate vicinity through which you laboriously made your way, the towering statues of snow-clad Alps, gazing down from the distance, awakened in you feelings of the sublime and holy (Mann 1924/1996, p. 462).

As the car bounced along the streets paved with bricks, past one poor little frame house after another, the massive railroad viaduct remained brokenly within view. It would not go away. This was the Swede's first encounter with the manmade sublime that divides 
and dwarfs, and in the beginning it was frightening to him, a child susceptible to his environment even then, with a proclivity to be embraced by it and to embrace it in return. (Roth 1997, p. 219-220)

These descriptions are about sublime objects - namely the Alps and a massive construction but also about the conscious experiences they trigger in the subjects: feelings of the sublime and holy, and a complex dynamic experience involving fear and the impression of being embraced by the environment but also, eventually, embracing it.

Beyond such descriptions, there is much controversy about what the experience of the sublime is. Some authors have claimed that it is appropriate only to natural entities, such as huge and steep mountains, starry night skies, waterfalls, grand canyons, deserts (see Brady, 2013, who acknowledges a few exceptions to this claim, such as land-art). Other authors have argued to the contrary and claimed that at least some human artefacts can also be sublime, as the passage from Roth suggests (for contemporary art, see Lyotard, 1991/1994). Another controversy concerns the relationship between the sublime and beauty. Some philosophers, most notably Edmund Burke (1759/1998) and Immanuel Kant (1790/2000), have defended a form of aesthetic dualism and claimed that the experience of the sublime is essentially different from the experience of beauty. ${ }^{1}$ Alternatively, following Arthur Schopenhauer (1819/1969), one might reject aesthetic dualism and consider the experience of the sublime to be an especially intense form of the experience of beauty.

In what follows, we can remain neutral with respect to these controversies. The only assumption that we will make is relatively consensual: experiences of the sublime are aesthetic experiences. More precisely, they are positively valenced aesthetic experiences, in the sense that they are the kind of experience that we seek out and want to reproduce (Prinz, 2014; Arcangeli, Dokic and Sperduti, 2018). This is so without undermining the fact that sublime experiences also involve negative feelings. Indeed, although we seek encounters with the sublime and take pleasure in them, there is a negative dimension to such eagerness, which has often been interpreted as fear (as depicted by Roth's passage).

Our aim in this essay is to provide a novel perspective on the experience of the sublime, which articulates its negative and positive aspects. Many scholars of the sublime have observed that when we are confronted with something indefinitely greater and more powerful than us, our perception and imagination are pushed to their limits, as we are trying to apprehend and make sense of what we experience. However, a detailed analysis of the kind of limit-experience underlying our

\footnotetext{
${ }^{1}$ For a neuroscientific perspective on aesthetic dualism, see Ishizu \& Zeki (2014), who claim that these experiences engage separate and distinct brain systems.
} 
confrontation with the sublime is still wanting. Here we provide a first step toward such an analysis. Our hypothesis is that the experience of the sublime involves an awareness of the limits of our cognitive capacities, which takes the form of a negative metacognitive feeling. In experiencing the sublime, we feel cognitively overwhelmed, being aware that we have reached the limits of our best cognitive ways of dealing with the world. As we will show, this hypothesis sets the stage for a componential approach to the experience of the sublime, which involves but does not reduce to the awareness of one's own cognitive limits.

We will start $(\S 2)$ by considering the vexed question of how to interpret the negative feelings involved in experiences of the sublime. We will point at the overwhelming aspect of experiences of the sublime as the key to understand what is proper to their negative side: they are driven by a certain kind of limit-experiences. In $\S 3$ we will offer an analysis of what limit-experiences are, by distinguishing between mundane and radical limit-experiences, where only the latter involve a metacognitive evaluation of a global cognitive failure. In $\S 4$ we will use this analysis to motivate our main hypothesis, namely that the experience of the sublime arises from a radical limit-experience. This hypothesis, however, leaves the overall positive valence of experiences of the sublime unexplained. In $\S 5$ we will explore different ways in which a subject can try to overcome or accommodate the negative evaluation involved in radical limit-experiences and suggest that only one of them is appropriate to experiences of the sublime.

\section{OVERWHELMINGNESS}

There is a wide consensus about experiences of the sublime being mixed feelings, which involve positive and negative evaluations. Here is how Brady (2013, p. 40) summarizes this point:

[T] he majority of accounts associate the sublime with mixed emotions. These emotions are described in various ways, but the idea is consistently expressed as a mix of negative and positive valences, with certain negative feelings (awe, terror, etc.) felt alongside positive ones (exaltation, admiration).

Experiences of the sublime differ from many other aesthetic experiences in involving strong negative emotions. Different views have been held about the nature of these emotions. Burke famously claimed that experiences of the sublime involve fear and terror, ${ }^{2}$ and Kant followed him at least in part,

\footnotetext{
${ }^{2}$ See, e.g., Burke (1759/1998, Part I Section VII).
} 
suggesting that we evaluate the sublime as fearful while knowing that we are not in danger. ${ }^{3}$ More recently, Cochrane (2012) put forward the more general claim that experiences of the sublime involve a "feeling of self-negation". ${ }^{4}$ Our own view of the negative affective evaluation associated with the sublime is congenial to Cochrane's and will be articulated below ( $§ 4)$.

However, if involving negative emotions is a necessary condition of the experience of the sublime, it does not seem to be a sufficient condition. Some aesthetic experiences involve negative emotions but do not fall under the traditional category of the sublime. Consider terrible beauty, for instance (Korsmeyer, 2005). Some artworks give rise to overall positive aesthetic evaluations but at the same time to negative emotions, such as disgust or even fear - think of, e.g., Francisco Goya's Saturn Devouring his Son (1823) or Francis Bacon's Head VI (1949). Or consider a lake whose surface is beautifully iridescent because of human pollution: we can certainly find it beautiful, although our experience is tinged with negative feelings (assuming that we know that it is spoiled by human activity).

What does characterize an experience of the sublime, then, in contrast with other aesthetic experiences involving negative emotions, including terror and fear? One answer is that experiences of the sublime are overwhelming in a way experiences of, say, terrible beauty need not be. Several contemporary authors have emphasized the overwhelming character of such experiences:

This feeling [of the sublime] can be occasioned [...] when perceptually overwhelming properties of objects test and strain our perceptual faculties. (Crowther, 1989, p. 8)

The beautiful is associated with the form of an object, which involves qualities that are contained or bounded in some way, while the sublime, in its overwhelming magnitude or power, is associated with formlessness and limitlessness. (Brady, 2013, p. 56)

The sublime has properties which are difficult to encompass within the scope of perception or even imagination:

\footnotetext{
${ }^{3}$ See Kant $(1790 / 2000, \S 28)$. It is not clear what Kant exactly had in mind here. On one interpretation, the negative emotions involved in the experience of the sublime are simulated, rather than real emotions: it is as if we were afraid, although we do not really evaluate the sublime object as dangerous. For discussion of Kant's view of the sublime, see Crowther (1989). If we are right, the negative emotions involved in the experience of the sublime are not simulated; we really feel them, at least initially, as we will see in $\S \S 3-4$.

${ }^{4}$ The nature of the negative emotions involved in experiences of the sublime has also interested psychologists. Although many authors associate the sublime with fear (see, e.g., Eskine et al., 2012; Gordon et al., 2017; Chirico \& Yaden, 2018), most empirical studies do not show any physiological or neurological evidence linking the experience of the sublime with classical markers of fear (see Ishizu \& Zeki, 2014; Hur et al., 2018). A neuroimaging study by Ishizu \& Zeki (2014) found only the activation of brain areas less associated with the experience of fear (i.e., the cerebellum, especially of Crus II), while reporting that sublimity ratings of pictures of nature positively correlated with ratings of pleasantness.
} 
Our Imagination loves to be filled with an Object, or to grasp at any thing that is too big for its Capacity. (Addison, 1712, no. 412, 23 June)

Such natural descriptions of what the sublime does to us might also capture what sets apart the sublime and terrible beauty: most cases of the latter are not overwhelming (Brady, 2013, p. 172). This idea is intuitively plausible, but the notion of overwhelmingness itself is in need of elucidation. What does it mean to say that the sublime object overwhelms our perceptual and imaginative capacities? The hypothesis to be developed is that the experience of the sublime, in contrast to other aesthetic experiences, is overwhelming in the sense that it involves a certain kind of limit-experience.

\section{ANALYSING LIMIT-EXPERIENCES}

What is a limit-experience? There are not many descriptions, let alone analyses, of limit-experiences as such in the philosophical literature. A notable exception is Foucault, who contrasted the phenomenological project of "organizing a reflective examination of any aspect of daily, lived experience in its transitory form, in order to grasp its meaning", with more transgressive projects he found in Nietzsche, Bataille, and Blanchot, who "try through experience to reach that point of life which lies as close as possible to the impossibility of living, which lies at the limit of the extreme" (1991, p. 31; translation Jay, 2006, p. 91). The latter project is described as:

$[T]$ he task of "tearing" the subject from itself in such a way that it is no longer the subject as such, or that is completely "other" than itself so that it may arrive at its annihilation, its dissociation, It is this de-subjectifying undertaking, the idea of a "limit-experience" that tears the subject from itself, which is the fundamental lesson that I have learned from these authors (Foucault, 1991, pp. 31-2).

According to Foucault, then, limit-experiences have the following features:

- They are highly intense experiences.

- They concern a limit which is, or is experienced as, absolute, in the sense that there is nothing recognisable beyond it.

- They threaten our ordinary ways of thinking and interacting with the world.

- They involve significant changes at the level of self-awareness. 
Foucault was obviously concerned with quite radical limit-experiences, which have substantial implications for our view of ourselves in the world. This is not to say, though, that all limit-experiences are radical. Let us start with the intuitive idea that a limit-experience involves some cognitive capacity operating at its limits. The notion of limit at stake here is cognitive or epistemic. Any limit-experience is thus relative to a cognitive capacity. Now consider less radical, even mundane cases of limit-experiences. For instance, when we barely recognize a thing because we are dazzled by sunlight, or we are in the penumbra, or the thing is too far away, we have limitexperiences relative to our visual capacity. Similarly, when we can barely discriminate extremely high notes, we have a limit-experience relative to our auditory capacity. In these cases, some perceptual capacity of ours is "tested and strained", to borrow Crowther's phrase. It is worth trying to give a preliminary analysis of such mundane cases and then determining whether it can be generalized to the more radical versions.

\subsection{MUNDANE LIMIT-EXPERIENCES}

Let us take as our toy example of a mundane limit-experience a situation in which the subject hears the highest note that she can hear. This experience meets at least the following three conditions:

$\left(1^{*}\right)$ The subject has a (conscious) auditory experience of a particular high note.

$\left(2^{*}\right)$ The subject is not capable of a having a (conscious) auditory experience of any higher note.

$\left(3^{*}\right)$ The subject is somehow aware of the cognitive limitation described in $\left(2^{*}\right)$.

Let us comment on each of these conditions. The first condition ensures that the subject's limit-experience still involves a conscious exercise of her auditory capacity. In other words, the subject hears, even barely, a note, which happens to be the highest note that she can hear.

The second condition implies that a small change pertaining to the note would make it impossible to hear: if the note were just a little bit higher, the subject could not have an auditory experience of it. The subject has reached the limits of her auditory capacity.

The third condition states that there is something it is like to have a limit-experience. If this condition were not met, the subject could in fact reach the limits of her auditory capacity without knowing it, or more precisely without being aware of her auditory limitation. To have a limitexperience is to be aware of it as such. But how can we do that?

A plausible answer, consonant with recent theoretical and empirical work on metacognition (see, e.g., Beran et al., 2012; Proust, 2013; Schwarz, 2015), is that our awareness of reaching the limits of some of our cognitive capacities relies on implicit metacognitive cues. When we hear the 
highest note that we can hear, our informational relation to the world is suboptimal. Auditory processes are disfluent, and our experience itself may be unstable: now we hear the sound, now we don't. The vast literature on metacognition shows that our brain hosts subpersonal mechanisms that are sensitive to the quality of our cognitive processes, including whether they are fluent or not, in a way which generates metacognitive (noetic, epistemic) feelings such as familiarity, certainty and their opposites, unfamiliarity and uncertainty (see, e.g., Dokic, 2012). In this context, the suggestion is that we can feel that we have reached the limits of our auditory capacity, even before explicitly thinking about them.

Given the nature of the underlying metacognitive cues, namely signals of disfluency, incoherence, and instability, the subject's awareness of her auditory limits gives rise to a negative evaluation of her auditory capacity. Her limit-experience comes with the realization that there are sounds that defy her auditory discriminative abilities. She understands that she possesses a cognitive capacity appropriate to a category of entities (notes or sounds), but that her capacity can be used to access only some of these entities. She suspects that the world of notes or sounds exceeds what she can access with her ears. She is aware of a failure, or at least an incompleteness, of her mind.

We can now start moving beyond our toy example and generalize our analysis to all mundane limit-experiences. To have a mundane limit-experience with respect to a cognitive competence $\mathrm{C}$, which can be a single capacity (like auditory perception) or a multimodal cooperation of several capacities, and feature $\mathrm{F}$, the following conditions must be satisfied:

(1) The subject exercises $\mathrm{C}$, which produces a conscious experience of an instance $\mathrm{i}^{*}$ of $\mathrm{F}$.

(2) C cannot produce an experience of another instance of $\mathrm{F}$ whose experienced value is either higher or lower than that of $i^{*}$.

(3) The subject is aware of the cognitive limitation stated in (2) thanks to her metacognitive experience of the way $\mathrm{C}$ is exercised in (1).

Condition (2) states that what is experienced via $\mathrm{C}$ is an extreme value of $\mathrm{F}$, so that it is impossible to experience via $\mathrm{C}$ either a higher or a lower value. The latter covers the case in which someone hears the lowest note that she can hear, which is also a mundane limit-experience. ${ }^{5}$ Other cases of mundane limit-experiences are also accounted by these conditions. Suppose $C$ is visual perception and $\mathrm{F}$ is distance. The subject has a limit-experience with respect to $\mathrm{C}$ and $\mathrm{F}$ only if (1) she has a visual experience of something being very very far away, (2) she cannot see anything as being farther away, and (3) she is aware of her visual limitation with respect to distance, while of ${ }^{5}$ This point should be kept in mind when we will come back to the experience of the sublime. Although the sublime is standardly associated with grand, immense or monumental entities, cases of infinite smallness can also be sublime, as Burke was clearly aware of. 
course realising that many distant things cannot be seen. In this case too, the metacognitive evaluation involved in (3) is negative, since it points to a failure of visual perception to encompass all cases of distance. The horizon is too far for us to see where it is exactly.

\subsection{RADICAL LIMIT-EXPERIENCES}

Mundane limit-experiences do not have the features that have been ascribed to their radical versions. First, they need not be highly intense experiences (although being dazzled by sunlight can be painful). Second, they concern a limit which need not be experienced as absolute. The failure of the relevant capacity can be compensated by other cognitive capacities. For instance, the subject can make sense of distances beyond the scope of her visual capacity: she can imagine or at least conceive them. We can conceive of a distance independently of its visible properties. Third, mundane limit-experiences do not threaten our ordinary ways of thinking and interacting with the world. When I experience the limits of my auditory capacity, I do not thereby experience global limitations of my ordinary ways of dealing with the world; I still have many cognitive ways to deal with the situation. For instance, I conceive of sounds that you can hear but that I cannot. Fourth, having a mundane limit-experience does not prevent me from experiencing myself as a cognitive agent in the world. Although I experience one of my cognitive capacities (e.g., audition) on the verge of failing me in dealing with the world, I still feel cognitively connected to the world in many other ways. There is no reason, then, that mundane limit-experiences bring about substantial changes at the level of self-awareness and question my identity as a cognitive agent in the world.

What, then, makes both mundane and radical limit-experiences members of the same mental category? In fact, the schematic analysis offered above for mundane limit-experiences can be adapted to deal with more radical limit-experiences. The main adjustment concerns the scope and complexity of the subject's metacognitive awareness. Suppose that there is a feature F whose instance can be experienced as extreme relative to $\mathrm{C}$ but without any possible compensation by some other cognitive competence at the subject's disposal. In other words, C cannot be used to apprehend more (or less) of F, and the subject cannot apprehend more (or less) of F by any other cognitive means. If the subject is metacognitively aware of this predicament, the relevant instance of F will appear to strain the subject's whole mind. She would feel an "absolute" cognitive limitation. There would be no cognitive refuge - or so it would seem to her.

Therefore, we have a radical limit-experience when conditions (1)-(3) above are met, with respect to some competence $\mathrm{C}$ (e.g., perception, imagination, ordinary thought, or a set of such capacities), but also a fourth condition, which describes the subject's awareness of her global 
cognitive failure:

(4) The subject is aware that no other competence C' at her disposal can overcome the cognitive limitation of $\mathrm{C}$ with respect to the relevant instance of $\mathrm{F}$.

While the metacognitive awareness described in (3) is local, the metacognitive awareness described in (4) is global. The kinds of metacognitive cues underlying both types of awareness can be similar, though. The subject might try to make sense of the relevant instance but get disfluency signals corresponding to failures of "comprehensibility" (Silvia, 2008). The subject feels that she cannot really identify or categorize what she is experiencing. It seems to her that her best cognitive attempts to deal with the world are on the verge of failing her at once, and that there is more to the world than what she can represent.

The resulting experience would show all the features of a radical limit-experience. First, it would certainly be intense, because of its global character. Second, it would involve the experience of an absolute cognitive limitation, and not merely a relative one. Third, it would threaten our ordinary ways of dealing with the world, as the relevant instance would overwhelm perception, imagination and ordinary thought at once. Fourth, as the subject experiences her whole mind on the verge of failing her, she would have the feeling of losing her cognitive connection with the world and her place in it as a determinate cognitive agent. Her sense of familiarity with the ordinary world would fade away, and what she experiences would seem radically novel and strange.

Are there features $\mathrm{F}$ such that their instances can strain our whole mind? We would like to suggest that experiences of the sublime involve precisely such instances, and that features $\mathrm{F}$ in this case are those that are traditionally associated with the sublime, namely vastness and power. If this suggestion is correct, experiences of the sublime involve radical limit-experiences. ${ }^{6}$

\section{THE EXPERIENCE OF THE SUBLIME}

As we have observed in $\S 2$, many descriptions of the sublime insist on its overwhelming character. As Burke put it, "the mind is so entirely filled with its object, that it cannot entertain any other" (1759/1998, p. 53). When confronted with the sublime, our most basic cognitive capacities, including perception, imagination and ordinary thought, are tested and strained. The experience of the sublime involves a radical limit-experience. We feel that we have reached the limits of what we thought were our best cognitive ways of dealing with the world.

Features traditionally associated with the sublime have to do with spatial, temporal or

\footnotetext{
${ }^{6}$ Since here we are interested in experiences of the sublime, we can remain neutral about whether there are features other than vastness and power whose instances are capable of triggering radical limit-experiences.
} 
conceptual vastness (in the case of what Kant dubbed the "mathematical sublime"), as well as power (in the case of the "dynamical sublime"). Consider the example of the horizon again. When we look at the horizon, we barely see the longest distance we can see, but we know that there are even longer distances, which we cannot see. Here, our visual limitation is compensated by other cognitive capacities, such as imagination and thought. Although we cannot look beyond the horizon, we can imagine or conceive many distances beyond the horizon. Now suppose we are trying to represent an infinite distance. Here, our perception, imagination and ordinary thought may fail at once, and we have a radical limit-experience with respect to space and its dimensions. To quote Burke again, "infinity has a tendency to fill the mind" (1759/1998, p. 67), and to exhaust our habitual cognitive ways of dealing with the world. Similarly, when Addison observed that the sublime is "too big" for the capacity of imagination (see $\$ 2$ ), he in fact pointed to a radical limitexperience. When we experience awe at the immensity of the universe while contemplating a cloudfree starry night sky in the middle of an August night up in the Alps, the universe is not just experienced as very, very big. Rather, it is experienced as (almost) too big for our perceptual, imaginative and even intellectual capacities, which are transcended by the sublime scene.

We have suggested above (§3.2) that radical limit-experiences involve a breach of familiarity with respect to the world, which appears radically novel and strange. One might object that there is nothing strange or novel about viewing a mountain range from below or looking down from the top of a peak. After all, these are rare but often familiar situations. However, we are referring here to the experiential level of primitive evaluations or "appraisals" of the world (Moors et al., 2013). The object or scene feels radically novel and strange, even impossible to categorize using our standard cognitive frames. This experience is compatible with our belief that we are in a familiar setting. ${ }^{7}$

The connection between the notions of limit-experience and strangeness is explicit in the following passage of Don DeLillo's Point Omega, in which the main character describes his experience of the desert: "The desert was outside my range, it was an alien being, it was science fiction, both saturating and remote, and I had to force myself to believe I was here" (DeLillo 2010). The desert is experienced by the character as "outside the range" of his perception and imagination, and thus as being radically strange ("alien" and "remote"), in a way which shakes his belief that he has a definite, objective place in the world.

The hypothesis under consideration is not that the experience of the sublime $i s$ a radical limitexperience (with respect to space, time, number or power), but that the latter is a core component of the former. Although the intensity of the experience of the sublime at least partly derives from the

\footnotetext{
${ }^{7}$ There is an interesting issue, which we must set aside here, about whether our belief can eventually penetrate our experience and make us used to the object or scene, which would cease to trigger experiences of the sublime.
} 
intensity of a radical limit-experience, they seem to have opposite valences. As already observed, the experience of the sublime has an overall positive valence. ${ }^{8}$ They are the kind of experience that we want to maintain and seek for. In contrast, to the extent that a radical limit-experience involves an evaluation of our whole mind as failing us, it has a negative valence. Thus, our hypothesis is that a radical limit-experience provides the negative dimension of the experience of the sublime, which is eventually counter-balanced, or accommodated, by an overall positive evaluation of the world (see $§ 5)$.

This hypothesis best explains a central feature of the experience of the sublime, namely that it involves a "feeling of self-negation" (Cochrane, 2012). The subject who is having a radical limitexperience is in a peculiar situation. She experiences an extreme value of some property, such as size, in a region of phenomenal space in which her discriminatory abilities are very poor and unreliable, while being aware that she cannot do better by any other cognitive means. This creates epistemic angst, and more precisely high subjective uncertainty about what exactly she is experiencing. Something can be visually measured as very very big, but when the subject feels that it is too big for her visual capacities and finds no other way of measuring it, it is apprehended as barely measurable. For instance, the subject looks at the starry night sky and is struck by the immensity of the universe, whose boundaries seem to be undrawable, and by the extremely numerous stars that it hosts, which seem uncountable. Or, (if the artistic sublime is possible), consider Anish Kapoor's Descent into Limbo (1992), which triggers the experience of an unfathomable black hole in the ground. More generally, the subject feels that her perceptual, imaginative and intellectual capacities can barely cope with the apparent vastness of the object. As a result, at least while she is focusing on the object, she feels indefinitely smaller or less powered and gifted than it.

In these examples, the feeling of self-negation is not to be understood merely as the feeling of being very very small. Psychological studies have shown that subjects experiencing awe, which is also triggered by extremely vast entities, tend to report feeling small, humble, or insignificant (Piff et al., 2015). These reports are best interpreted as the metaphorical expression of the subjects struggling to find their place in the vastness of what they experience. They feel that such a place can hardly be found, not that it is determinate but tiny. Of course, we might have the impression of literally shrinking when we are confronted with the "towering statues" of the Alps, their huge

\footnotetext{
${ }^{8}$ This is in line with experimental treatment of the sublime. In a study investigating its cognitive-affective profile on a large scale, Pelowski et al. (2019) have found that this kind of experience is mostly reported (90.8 \%) as associated with positive emotions (e.g., pleasure). Their findings cast doubts on psychological studies on awe (an emotion frequently associated with the sublime; see below) presupposing that experiences of the sublime are mainly negatively valenced (see, e.g., Gordon et al., 2017; Chirico \& Yaden, 2018).
} 
spatial and temporal extensions, but what characterizes the type of limit-experience involved in experiences of the sublime is the point where we feel like wholly disappearing from the world. To the extent that what we experience feels so real but we do not know where we fit in the picture, we feel that we do not belong to the real world anymore. Like the character of Point Omega described above, we tend to believe that we are not here, that we have fallen out of this world.

The next issue is of course to explain how we are supposed to move from a radical limitexperience, which has a negative valence, to the positive evaluation inherent to our experience of the sublime. At this point, it is useful to borrow Keltner and Haidt (2003)'s use of the Piagetian distinction between assimilation and accommodation. Whereas assimilation is the process of bringing the object of our experience under ordinary or already familiar categories, accommodation requires some "paradigm shift", namely substantial changes in our cognitive ways of dealing with the object, such as entirely new categories or ways of thinking. These authors suggest that awe, which they associate with the sublime (as they acknowledge, sublime objects are awe-inspiring), leaves the subject in need of accommodation and not merely assimilation. Our suggestion is that radical limit-experiences involved in experiences of the sublime also create a need for accommodation. For instance, there is no easy way we can deal with our inability to cope with the sublime object, especially since its properties are potentially threatening. Now the fact that experiences of the sublime have an overall positive valence has to do with the specific way their underlying limit-experiences are accommodated.

In the next section, we shall distinguish several ways in which a radical limit-experience can be accommodated and try to identify which of them best explains our experience of the sublime. In the meantime, let us summarize our account of the relationship between experiences of the sublime and radical limit-experiences. When we are confronted with the sublime, our experience has a narrative structure, which can be pictured as follows (Fig. 1):

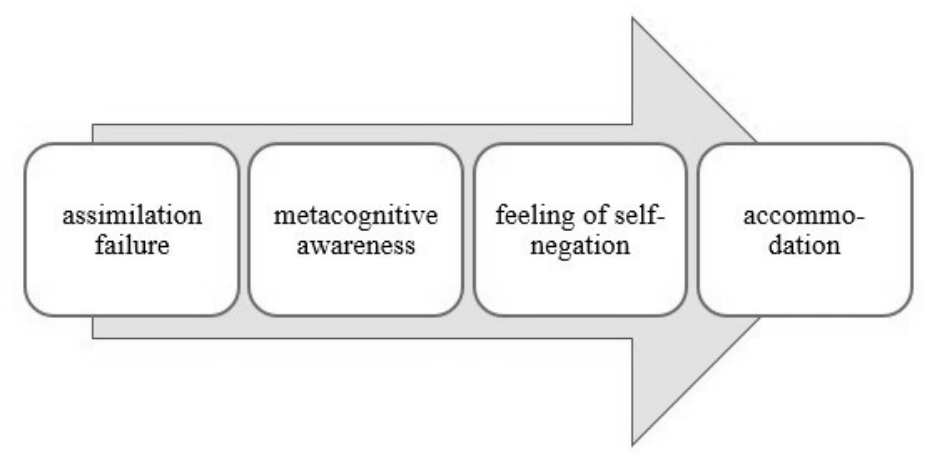

Fig. 1: The narrative structure of the experience of the sublime

On this picture, the experience of the sublime has four distinct moments. We talk of 
"moments" here rather than steps or phases, because we do not want to suggest that the relevant narrative structure is linear. Although the experience of the sublime is certainly dynamic, some of these moments might happen at the same time, even though they might be in tension. Moreover, the process is reversible and might also be cyclic.

The first moment is the confrontation with the sublime object, which provokes a global assimilation failure: the object challenges (what we thought were) our best cognitive capacities. This is the moment where the sublime object fills the whole mind and attracts the subject's full attention. ${ }^{9}$

The second moment is the subject's realisation of her global cognitive failure, in the form of a metacognitive experience. This moment shows a modification of the first moment, since the subject must somehow reflect on her cognitive predicament and thus at least partly draw her attention away from the sublime object. Even though the subject starts resisting full absorption by the sublime object, the latter may still be experienced as at least tending to invade her whole mind.

As we have seen, the metacognitive awareness of one's global cognitive failure has a negative valence. It also yields subjective uncertainty as to one's place in the world as a cognitive agent. Thus, the third moment of the experience of the sublime is the feeling of self-negation: the subject does not feel to be part of the world anymore.

The latter three moments correspond to a radical limit-experience with respect to extreme values pertaining to vastness or power. They create a need for accommodation. The fourth and last moment of the experience of the sublime involves a specific type of accommodation, which explains how this experience can have an overall positive valence as an aesthetic experience. Consider the following narrative account of the experience of the sublime:

[T]he initial feeling of the sublime is an uncomprehending awe, which not only "lowers" or humbles us, but inspires us to hope for and aspire to greater heights of comprehension (or behavior); we then work to attain to such comprehension, feel satisfaction at comprehension of order in the object (i.e., find it beautiful) and, finally, feel informed awe at the conjoined power and order of the now fully appreciated object (the "true" or complete sublime, and the peak of beauty). (Zuckert, 2003, pp. 877-878)

Independently of the controversial view that the sublime is the peak of beauty (see $§ 1$ ), what

\footnotetext{
9 This is the moment described as 'immersion' in Arcangeli, Dokic and Sperduti (2018). There we argued that immersion, an experience which tends to blur the phenomenological boundary between the self and the world, is a necessary condition of the experience of the sublime. However, as it will become clear below, this tendency must be resisted in order to reach an aesthetic evaluation of the sublime object.
} 
Zuckert describes here is, in our terms, the move from the need of accommodation to actual, aesthetic accommodation.

However, as we shall see, there are different ways in which the subject can try to accommodate a radical limit-experience. Although we cannot give a full account of the nature of aesthetic accommodation, which characterizes the experience of the sublime, the distinction between different types of accommodation will hopefully pave the way to a better understanding of the nature of the experience of the sublime.

\section{THREE TYPES OF ACCOMMODATION}

\subsection{ESTRANGEMENT}

The first way to accommodate a radical limit-experience is "estrangement". It consists in indulging in self-negation in a way which may lead to a temporary state of depersonalisation (Sierra, 2009). The object or scene may be so overwhelming that the subject does not feel real anymore. Such a state is psychologically unstable. Depersonalisation leads to derealisation: the subject cannot be depersonalized and at the same time feel that what she is experiencing is real. The limit-experience is accommodated at the cost of denying both the reality of oneself and what in the world is experienced. Depersonalized and derealized subjects have an athymic temperament; they say that they do not enjoy emotions (but see Billon, 2017, for the claim that they may have emotions after all).

Estrangement does not necessarily come to depersonalisation, but it involves at least a tendency to the latter, which gives rise to strong negative emotions. This seems to be in line with Foucault's description of radical limit-experiences (see §2). He says that the subject "may arrive at its annihilation", that the limit-experience "tears the subject from itself". Arguably, Foucault was interested in the tipping point where the tendency to depersonalisation is still compatible with the feeling that the object of one's experience is real, in a way which gives rise to an apparently "impossible" or "paradoxical" experience. However, this is not the end of it, because although the tendency to depersonalisation has a negative valence, Foucault certainly insisted on the positive, transformative dimension of radical limit-experiences, which suggests that he was after a further type of accommodation.

\subsection{FULLNESS}

The second way to accommodate a radical limit-experience is "fullness". Radical limit-experiences have a negative valence to the extent that they involve an evaluation of one's cognitive capacities as 
failing us. Now suppose that we manage to change this evaluation and somehow conceive of the limits of our mind as mere limits, beyond which there is literally nothing. On this evaluation, there would be nothing wrong with our cognitive capacities. The limits of our mind, or more precisely of what we can cognize, would coincide with the limits of the world.

The experience which results from such an evaluation is that of an identification, or at least a close union, between oneself and the world (recall the "proclivity to be embraced" by the environment stressed by Roth). It might take the form of a mystical experience (recall Mann's feelings of holy); indeed Wittgenstein wrote in the Tractatus: "Feeling the world as a limited whole - it is this that is mystical” (\$6.45). Independently of mystical or religious connotations, it might bring about a "sense of fullness", which Taylor (2007) describes as "an experience which unsettles and breaks through our ordinary sense of being in the world, with its familiar objects, activities and points of reference" (p. 5). The sense of fullness clearly has a positive valence; it feels good to be fully connected to the world, from which we are not estranged any more.

\subsection{DUALISTIC ACCOMMODATION}

The first two types of accommodation result in nondualistic experiences, namely experiences in which the distinction between subject and object is abolished or at least blurred. Non-dualistic experiences come in many different forms, as the following quotation makes clear:

Nondualistic experiences might be variously described as nirvanic, epiphanic, numinous, religious, flow, ecstatic, or oceanic - depending upon one's preferred philosophical or soteriological tradition. Characterizations of nondualistic experiences might deploy such metaphors as 'interpenetration' of subject and object, or 'fusion' of artist and work, or 'overcoming,' or 'dissolving,' or 'transcending' such binary oppositions as subjective and objective reality. All these idioms suggest that, under particular circumstances, sharp distinctions between such binary terms as self and other, or subject and object, are undone. (Krausz, 2009, p. 194)

The empirical literature (especially in psychology and anthropology) talks about "the dissolution of the sense of the self", "the loss of boundaries between self and world" - a phenomenon variously described as "ego dissolution", "ego disintegration", "ego loss" or "ego death" (Millière, 2017).

Estrangement and fullness are two ways of achieving ego-dissolution, although they have 
opposite valences. While estrangement feels bad, fullness feels good. In the former case, the world wins over the self, which is reduced to nothing, yielding a negative, depersonalisation-like experience. In the latter case, the self pervades the world, yielding a positive, hyper-familiarity experience in which everything feels self-related. Note that the literature acknowledges a similar distinction, between positively and negatively experienced ego dissolution (Millière, 2017, p. 3).

Although this is highly controversial, a case can be made for the view that the first two types of accommodation are incompatible with a genuinely aesthetic attitude. For aesthetic experiences must be dualistic and make room for some distinction between subject and object. This view is stated most clearly by Levinson (2016):

$[\mathrm{M}] \mathrm{ystical}$ experiences, as I understand them, cannot also be aesthetic ones, because in such experiences the distinction between subject and object effectively dissolves, and with it any sense of an object's properties as distinct from perception of them, and of the object as existing independently of the subject (p. 41)

Thus, if the experience of the sublime is to be an aesthetic experience, it should be dualistic. Indeed, a sublime object is not spontaneously experienced as an object among others, since it is overwhelming to the point that it fills the whole mind. So how can we restore the experiential distinction between subject and object from an experience which tends to (either negative or positive) ego dissolution?

Dualistic accommodation should involve a re-evaluation of the radical limit-experience as not being as radical as it seems. (In a sense, this is a way of evaluating the radical limit-experience as being at least partly illusory as regards its global scope, i.e., as resting on a metacognitive error.) The subject realizes that there is a cognitive refuge after all. She succeeds in mobilising novel or unsuspected cognitive resources that are not concerned by the limit-experience. For instance, she reevaluates what seems to her to be a radical limit-experience with respect to size by bringing in a sophisticated concept of infinity, which enables her to make sense of what she is confronted with. The subject is then able to restore her place in the world as a determinate cognitive agent.

Dualistic accommodation need not make the subject's experience less intense. The subject might still experience (comprehending) awe of the sublime object. How such an emotion should be analysed is another issue. It might be the sui generis attitude of being impressed by, and/or involve admiration for, the sublime object (see McShane, 2013, for discussion of some of the available options here). Alternatively, it might really be admiration for one's own cognitive success in comprehending the limit-experience, a view most notably associated with Kant (see Cochrane, 
2012, who describes Kant as holding a "heroic" theory of the sublime).

Dualistic accommodation need not yield an experience of the sublime. In some cases, the resulting experience won't be aesthetic at all. It is not obvious, for example, that what makes one's confrontation with a sublime object an aesthetic experience is merely admiration for the object of whatever agent is deemed responsible for it. For that matter, this could also be a religious experience, where the relevant agent is God or some divinity. Only some cases of dualistic accommodation are apt to produce an aesthetic experience. It is of course not the place to develop a full account of aesthetic experience here. Let us simply acknowledge that if such an account is applied to the experience of the sublime, it should identify the type of dualistic accommodation which is specific to the sublime, and contrasts it with other (e.g., religious) types of dualistic accommodation.

\section{CONCLUSION}

Our aim in this paper was not to give a full account of the experience of the sublime, but to offer an analysis of one of its core components, which we have identified as a radical limit-experience with respect to vastness or power. We argued that the negative component of the experience of the sublime consists in a negative metacognitive evaluation, more precisely an evaluation of our whole mind as failing us in dealing with the sublime object.

Our analysis constrains the explanation of how we move from a negative evaluation to a positive one, since the experience of the sublime eventually gains the status of a positive aesthetic experience. In the terminology used here, the radical limit-experience at the heart of the experience of the sublime creates a need for accommodation, i.e., the search for novel cognitive resources to cope with the sublime object. In general, an experience with a negative valence motivates the subject to find a way out, such as running away if the experience is fear. In the case of the sublime, the radical limit-experience has a negative valence due to a feeling of high uncertainty about one's cognitive capacity to cope with potentially threatening properties. As such, they motivate the subject to deal with the situation and diminish or remove uncertainty. However, what can and should be done is much less transparent as in the ordinary case of fear. That is why new ways of thinking must be invented or re-discovered.

We are also in a better position to explain the psychological nature of the experience of the sublime and to differentiate it from other aesthetic experiences, such as the experience of terrible beauty. The latter experience also involves some negative evaluation of the beautiful object but need not build on a limit-experience. For instance, we might be disgusted by Daniel Spoerri's "snarepictures" involving the remains of meals, plates and glasses fixed to a board and displayed on a 
wall. Our disgust, though, does not test and strain our cognitive capacities. In general, what is crucial to the experience of the sublime is not physical threat in itself (disgust, for instance, might be categorized as fear of being contaminated), but cognitive threat: what one fears when one is confronted with a sublime object is to lose one's cognitive capacity to deal with and understand the world.

The hypothesis that the experience of the sublime is driven by a limit-experience gives credit to Shapshay (2013)'s notion of "thick sublime", which essentially involves a cognitive play of ideas, in contrast with the "thin sublime", which is largely a non-cognitive, affective experience. On our account, the experience of the sublime is certainly thick, because it has a core metacognitive dimension, but it also involves an affective evaluation of our mind as failing us in dealing with the world.

We have argued that the kind of radical limit-experience triggered by vast or powerful entities is necessary but not sufficient to yield an experience of the sublime. To get an experience of the sublime, the subject must accommodate the cognitive overwhelmingness of the sublime in a way which restores the subject's place in the world and install an aesthetic relation to the sublime object or scene. As we have suggested, the same kind radical limit-experience can be accommodated in other ways, including estrangement and fullness. Thus, if our experience of the sublime is aesthetic, one of its core components is not. We take this to be a further virtue of our analysis since we can fruitfully compare and contrast experiences of the sublime with other experiences that are not aesthetic yet share a common element with the former. ${ }^{10}$

\section{REFERENCES}

Addison, J. (1712). On the Pleasure of the Imagination. In Addison, J. and Steele, R. (Eds), The Spectator.

Arcangeli, M., Sperduti, M. and Dokic, J. (2018). The Beautiful, the Sublime and the Self. In Cova, F. and Réhault, S. (Eds), Advances in Experimental Philosophy of Aesthetics. London: Bloomsbury, 175-196.

Arcangeli, M. et al. (2020). Awe and the Experience of the Sublime: A Complex Relationship. Frontiers in Psychology, doi:10.3389/fpsyg.2020.01340.

\footnotetext{
${ }^{10}$ We are very grateful to several audiences (in Athens and Paris) and to two anonymous referees for their valuable feedback. This study has been funded by the SublimAE project (ANR-18-CE27-0023), with the further support of the ANR-17-EURE-0017 FrontCog and the ANR-10-IDEX-0001-02 PSL.
} 
Beran, M., Brandl, J. L., Perner, J. and Proust, J. (Eds) (2012), Foundations of Metacognition, Oxford, Oxford University Press.

Billon, A. (2017). Mineness First: Three Challenges to the Recent Theories of the Sense of Bodily Ownership. In F. de Vignemont and A. J. T. Alsmith (Eds), The Subject's Matter. SelfConsciousness and the Body, Cambridge (MA), MIT Press, 189-216.

Brady, E. (2013). The Sublime in Modern Philosophy. Aesthetics, Ethics, and Nature. Cambridge: Cambridge University Press.

Burke, E. (1759/1998). A Philosophical Enquiry into the Origin of Our Ideas of the Sublime and the Beautiful. Edited by Adam Phillips. Oxford: Oxford University Press.

Chirico, A. \& Yaden, D. B. (2018). Awe: A Self-Transcendent and Sometimes Transformative Emotion. In The Function of Emotions, ed. Lench, H. (221-233), Springer, Cham.

Cochrane, T. (2012). The emotional experience of the sublime. Canadian Journal of Philosophy, 42(2): $125-148$.

Crowther, P. (1989). The Kantian Sublime, Oxford, Clarendon Press.

DeLillo, D. (2010), Excerpt: 'Point Omega', New York Times, Books, February $1^{\text {st }}$ (https://www.nytimes.com/2010/02/02/books/02book_excerpt.html).

Dokic, J., (2012). Seeds of Knowledge: Noetic Feelings and Metacognition. In M. Beran, J. L. Brandl, J. Perner, and J. Proust, (Eds.), Foundations of Metacognition, Oxford, Oxford University Press, 302-320.

Eskine, K. J., Kacinik, N. A., \& Prinz, J. J. (2012). Stirring images: fear, not happiness or arousal, makes art more sublime. Emotion, 12(5), 1071.

Foucault, M. (1991). How an 'experience-book' is born. In R. J. Goldstein and J. Cascaito (ed. and trans.), Remarks on Marx: Conversations with Duccio Trombadori, New York, Semiotext(e), $25-42$.

Gordon, A. M., Stellar, J. E., Anderson, C. L., McNeil, G. D., Loew, D., \& Keltner, D. (2017). The dark side of the sublime: Distinguishing a threat-based variant of awe. Journal of Personality and Social Psychology, 113(2), 310. 
Hur, Y. J., Gerger, G., Leder, H., \& McManus, I. C. (2018). Facing the sublime: Physiological correlates of the relationship between fear and the sublime. Psychology of Aesthetics, Creativity, and the Arts.

Ishizu, T. and S. Zeki (2014). A neurobiological enquiry into the origins of our experience of the sublime and beautiful, Frontiers in human neuroscience, 8: 891.

Jay, M. (2006). The Lifeworld and Lived Experience. In H. L. Dreyfus and M. A. Wrathall (Eds), $A$ Companion to Phenomenology and Existentialism, Oxford, Blackwell, 91-104.

Kant, I. (1790/2000). Critique of the Power of Judgment, edited by P. Guyer, translated by P. Guyer and E. Matthews. Cambridge: Cambridge University Press.

Keltner, D, \& Haidt, J. (2003). Approaching awe, a moral, spiritual, and aesthetic emotion. Cognition and Emotion, 17 (2): 297-314.

Korsmeyer, C (2005). Terrible Beauties. In M. Kieran (Ed), Contemporary Debates in Aesthetics and the Philosophy of Art, Malden (Mass.), Blackwell, 51-63.

Krausz, M. (2009). Creativity and Self-Transformation. In M. Krausz, D. Dutton and K. Bardsley (Eds), The Idea of Creativity, Leiden \& Boston, Brill, 191-204.

Levinson, J. (2016). Toward an Adequate Conception of Aesthetic Experience. In Aesthetic Pursuits. Essays in Philosophy of Art, Oxford, Oxford University Press, 28-46.

Lyotard, J.-F. (1991/1994). Lessons on the Analytic of the Sublime, translated by E. Rottenberg, Stanford University Press.

Mann, T. (1924/1996). The Magic Mountain, trans. by J. E. Woods. NYC, Vintage International.

McShane, K. (2013). Neosentimentalism and the valence of attitudes. Philosophical Studies, 164(3), 747-765.

Millière, R. (2017). Looking for the Self: Phenomenology, Neurophysiology and Philosophical Significance of Drug-induced Ego Dissolution. Frontiers in Human Neuroscience, Vol. 11, Article 245.

Moors, A., Ellsworth, P. C., Scherer, K., Frijda, N. H. (2013). Appraisal Theories of Emotion: State of the Art and Future Development. Emotion Review, 5(2), 119-124.

Pelowski, M., Hur, Y. J., Cotter, K. N., Ishizu, T., Christensen, A. P., Leder, H., \& McManus, I. C. (2019). Quantifying the if, the when, and the what of the sublime: A survey and latent class 
analysis of incidence, emotions, and distinct varieties of personal sublime experiences. Psychology of Aesthetics, Creativity, and the Arts.

Piff, P. K., Dietze, P., Feinberg, M., Stancato, D. M., Keltner, D. (2015). Awe, the Small Self, and Prosocial Behavior. Journal of Personality and Social Psychology, 108(6), 883-899.

Prinz, J. (2014). Emotion and aesthetic value. In E. Schellekens and P. Goldie (Eds.), The aesthetic mind: Philosophy and psychology. Oxford, Oxford University Press, 71-88.

Proust, J. (2013). The Philosophy of Metacognition: Mental Agency and Self-Awareness, Oxford, Oxford University Press.

Roth, P. (1997). American Pastoral. NYC, Vintage International.

Schopenhauer, A. (1819). Die Welt als Wille und Ausstellung, translated as The World as Will and Representation, Vol. I. by E. F. J. Payne (1969). New York, NY: Dover Publications.

Schwarz, N. (2015). Metacognition. In M. Mikulincer, P. R. Shaver, E. Borgida and A. Bargh (Eds), APA Handbook of Personality and Social Psychology: Attitudes and Social Cognition, Washington (DC), APA, 203-29.

Shapshay, S. (2013), Contemporary Environmental Aesthetics and the Neglect of the Sublime, British Journal of Aesthetics, 53 (2), 181-198.

Sierra, M. (2009). Depersonalization: A new look at a neglected syndrome. Cambridge: Cambridge University Press.

Silvia, P. J. (2008). Interest: The Curious Emotion. Current Directions in Psychological Science, $17(1), 57-60$

Taylor, C. (2007). A Secular Age, Cambridge (MA), Harvard University Press.

Wittgenstein, L. (1922). Tractatus Logico-Philosophicus. Trans. C. K. Ogden, London, Routledge \& Kegan Paul.

Zuckert, R. (2003). Awe or Envy: Herder contra Kant on the Sublime. The Journal of Aesthetics and Art Criticism, 61(3), 217-232. 